\title{
MORALIDAD Y PATRIOTISMO: EL PUNTO DE VISTA DE ALASDAIR MacINTYRE
}

\author{
Morality and Patriotism from the perspective of Alasdair Maclntyre
}

Resumen: La inclusión del patriotismo dentro de la moralidad depende de cuál sea el fundamento de la legitimidad de las decisiones morales. El artículo analiza el texto de Alasdair Maclntyre, Is Patriotism a Virtue?, y pone en relieve la complejidad de referirse a los términos 'patriotismo' o 'nación' en el caso de situaciones políticas como, por ejemplo, la española.

Palabras clave: A. Maclntyre, patriotismo, virtud, moralidad

Abstract: The inclusion of patriotism within morality depends on which grounds are regarded as the root of moral decision's legitimacy. The paper analyses Alasdair Maclntyre's Is Patriotism a Virtue? and points out the complexity of using the terms such as 'patriotism' or 'nation' when talking about political situations such as the Spanish.

Keywords: A. Maclntyre, patriotism, virtue, morality

\section{Introducción}

Alasdair Maclntyre publicó Is Patriotism a Virtue? en 1984, tres años más tarde que After Virtue, obra con la que sorprendió el mundo académico por la defensa de tesis aristotélicas que situaban la virtud en el centro de la filosofía moral. En sus obras posteriores, Whose Justice, Which Rationality (1988), Three Rival Versions (1990) y Dependent Animal Rationals (1999), por nombrar las más conocidas, Maclntyre fue 
perfilando su pensamiento hasta declararse defensor de la tradición que, empezando por Aristóteles, fue retomada por Agustín y Tomàs de Aquino.

La idea fundamental de After Virtue, obra que dejaba atrás el marxismo defendido por el autor en sus primeros años académicos, hacía hincapié en la virtud con base en la cual se definían los otros tres conceptos que constituyen el eje central de su propuesta filosófica: 'práctica', 'unidad narrativa' y 'tradición'. Partiendo de estos conceptos, Maclntyre expone cuál es la comunidad más adecuada para hacer posible el ideal de 'vida buena'.

La práctica es una actividad cooperativa regida por un conjunto de normas que los participantes se avienen a cumplir; la participación en la práctica favorece la adquisición de virtudes entendidas como calidades adquiridas. Así, por ejemplo, es a través de la participación reiterada en la práctica del ajedrez que se puede adquirir la virtud de la paciencia, una cualidad que resulta indispensable si se quiere sobresalir en el ajedrez. La práctica es presentada como el terreno donde se muestran las virtudes, si bien estas cualidades no se ejerzan sólo en las prácticas. Hablar de éstas es hablar de actividades que se llevan a cabo en cooperación con otras personas. La participación en las prácticas genera bienes internos y bienes externos para el sujeto que participa en ellas. Los bienes externos son contingentes y fáciles de reconocer también por aquellos que no participan en la práctica. En cambio los bienes internos sólo pueden ser reconocidos por los participantes en la práctica. Llegar al reconocimiento y a conseguir los bienes internos a una práctica pide la adquisición previa de las virtudes que influyen en la manera de realizar una práctica. Con las virtudes, el sujeto tiene una apreciación cabal de sí mismo y de los demás, y una conducta que se corresponde con esta apreciación. El conocimiento verdadero de los méritos ajenos y de las insuficiencias propias propicia una buena disposición para aceptar los modelos de excelencia de una práctica y para obedecer las reglas por las que aquélla se rige.

Los modelos de excelencia son referencias al buen ejercicio de una práctica y ejercen una función de autoridad que tiene que ser reconocida y aceptada por los 
participantes en ella. Hay que decir lo mismo de las reglas de una práctica, que la definen en lo que es, y que han de ser respetadas para que la práctica continúe.

Maclntyre encaja las prácticas en la tradición, un término al que da un significado del todo inusual. Una tradición es una forma de ver la vida y de ver el mundo que se expresa en una serie de ideas o acuerdos fundamentales de las que participan todos los integrantes de la tradición. Las tradiciones tienen un punto de partida y se desarrollan a lo largo del tiempo; cada generación acoge estos principios fundamentales que provienen del pasado y que identifican la tradición, los vuelve a considerar y los proyecta hacia el futuro. Ejemplos de tradiciones lo son el cristianismo, el islamismo y el judaísmo.La tradición ofrece el contexto necesario para que cada persona entienda de dónde deriva su identidad, y dónde se enmarcan las aspiraciones morales de su vida. La tradición aporta elementos que confieren sentido tanto a las prácticas como a la búsqueda de los bienes individuales. Considerado individualmente, aislado de la tradición, el sujeto no podría ejercitar las virtudes ni lograr su bien moral. Todo pensamiento lo es en y desde una tradición:

“Porque la historia de mi vida está siempre incorporada en la de aquellas comunidades de las que derivo mi identidad (...) La posesión de una identidad histórica y la posesión de una identidad social coinciden (...). Así, pues, yo soy en gran parte lo que he heredado, un pasado específico que está presente, en alguna medida, en mi presente." (Maclntyre, 1981: 221)

El sujeto protagonista de las prácticas y de las tradiciones en las que Maclntyre piensa es aquél que entiende la vida humana como una unidad narrativa. El yo, dice el autor, no puede ser considerado como un conjunto de secuencias o una colección de roles diferentes. La vida de cada persona es la historia de una narración de la que es actor y, en parte, también autor. Los actos de la vida tienen sentido en un contexto definido por finalidades, por creencias y situaciones. Por eso dice Maclntyre que somos protagonistas de nuestra narración y actores secundarios de las narraciones de los otros. El sentido de la vida humana deriva de entenderla como una 
unidad con finalidad. Sólo entendiendo la vida humana como una vida que se extiende a lo largo del tiempo, con un comienzo, un desarrollo y un final, se puede hablar de identidad personal y de un sentido de la vida humana. El pasado o el futuro de cualquier vida tiene sentido desde el presente en que se conecta la experiencia pasada con

la

planificación

futura.

\section{El concepto de patriotismo}

Con estas categorías de fondo, virtud, práctica, tradición y unidad narrativa, Maclntyre aborda el tema del patriotismo en un artículo en que, como dice el título, se plantea si el patriotismo es una virtud.

Antes, pero, de entrar en la exposición del concepto de patriotismo, que es la traducción exacta de la palabra que emplea Maclntyre (patriotism), se hace necesario distinguir entre 'nación' y patria', y sus derivados, 'nacionalismo' y 'patriotismo'. El Diccionario de la Real academia Española (DRAE) define 'nación' con los siguientes términos: la nación es un "Conjunto de personas de un mismo origen y que generalmente hablan un mismo idioma y tienen una tradición común." $Y$ 'nacionalismo' como la "Ideología que atribuye entidad propia y diferenciada a un territorio y a sus ciudadanos, y en la que se fundan aspiraciones políticas muy diversas."

En cuanto a la definición de 'patria', le DRAE afirma: "Tierra natal o adoptiva ordenada como nación, a la que se siente ligado el ser humano por vínculos jurídicos, históricos y afectivos.." Y del 'patriotismo', que es un "Amor a la patria".

La definición de 'nación' que ofrece el DRAE da las características de identificación de una comunidad para pueda ser considerada una nación, esto es, que los miembros que la integran tengan un mismo origen, hablen un mismo idioma y tengan una tradición común. El nacionalismo es presentado como una ideología que considera la comunidad con unas características que la hacen diferente de otras comunidades. En cuanto a la patria, el DRAE la relaciona con la nación a la que se 
sienten ligados sus habitantes por diferentes lazos. La expresión 'patriotismo', en cambio, expresa el sentimiento sentido hacia la patria o nación

Comparando 'nacionalismo y 'patriotismo se ve claro que, mientras la primera se refiere a una actitud política e ideológica, en la definición de la segunda se alude sólo a los vínculos afectivos hacia la patria.

Maclntyre define el patriotismo en estos términos: “(...) es una especie de lealtad a una nación en particular, que sólo pueden mostrar los que poseen aquella nacionalidad en particular." (Maclntyre, 1984: 4).

Desglosando los términos de la definición tenemos que:

a) El patriota es fiel a su nación, es decir, guarda los compromisos contraídos con su nación y se siente afectivamente ligado a ella. El patriota es leal a su nación por sus características, méritos e hitos logrados. La actitud de patriotismo incluye un tipo de agradecimiento a la nación que Maclntyre distingue del agradecimiento que se puede tener hacia una institución por los beneficios que se han recibido. Las características de la nación a la que se pertenece y los beneficios recibidos sólo pueden ser razones parciales del patriotismo. (Maclntyre, 1984: 5)

b) El patriotismo se manifiesta hacia una nación en particular; se excluye, por lo tanto, un referente que no sea concreto.

c) Como actitud, el patriotismo se atribuye a quien pertenece, por su nacionalidad, a aquella nación.

Hasta aquí se han dibujado las características generales del patriotismo, pero este concepto no se ha tomado siempre en un único sentido. Así, Maclntyre señala dos formas históricas diferentes de entender la palabra 'patriotismo'. Una forma de concebirlo, implícita en el siglo XIX y también en las McGuffey Readers ${ }^{1}$, era considerar el patriotismo como una virtud; esta idea contrasta con la manera de presentar el término, propia del años sesenta, que tomó el 'patriotismo' como un vicio.

\footnotetext{
${ }^{1}$ Los McGuffey Readers fueron libros de texto utilizados por las escuelas americanas desde mediados del s. XIX hasta mediados del s. XX.
} 
La tarea que Maclntyre se propone desarrollar en el artículo no es la de ofrecer razones que permitan tomar partido por una u otra tesis, sino más bien la de aclarar los puntos de fricción entre ambas tesis.

En primer término, es necesario distinguir el concepto de patriotismo de otros conceptos afines con los que se podría confundir, puesto que no a toda defensa de la propia patria se puede llamar 'patriotismo':

1) En primer lugar, nos referiremos a la actitud de aquellas personas que defienden su nación porque la juzgan exponente de algún ideal moral. Así, por ejemplo, Maclntyre cita las palabras de Émile Durkheim cuando defendía a Francia porque la consideraba la madre de la civilización. Esta es una actitud de admiración hacia la nación que, sin embargo, cabe distinguir del patriotismo por dos razones:

a) Cuando alguien defiende a su nación porque cree que abandera un ideal valioso o que es adalid de alguna cuestión fundamental da muestras de considerar más importante el ideal o la cuestión fundamental que la propia nación; lo que se estima más preciado en esta actitud es el ideal por el que se está agradecido a la nación, no la nación misma. Así, de las palabras de Durkheim podemos deducir que para él es primero la civilización que la nación francesa dado que la admiración por Francia proviene del convencimiento de que es causa de la civilización.

b) Por otro lado, si el ideal que defiende una nación es la razón para serle leal, cualquier persona, sea o no ciudadana de una nación, que tenga en alta consideración aquel ideal, se podría considerar patriota, aunque no formara parte de aquella nación. De este modo, un americano que defendiera a Francia por las mismas razones que Durkheim lo hace, tendría que ser considerado un patriota francés.

2) En segundo lugar, no se puede llamar 'patriotismo' a cualquier clase de exaltación de la patria propia que no tenga nada que ver con las características de la nación. Desde el punto de vista de Maclntyre, el patriotismo tiene que ver con la lealtad a la nación debido a sus características, a sus méritos o a los hitos que ha logrado. 
Queda claro, pues, que el patriotismo es una actitud que vincula al ciudadano a la nación a que pertenece, y que, debido a las características de la nación, el ciudadano le es leal.

\section{El patriotismo, ¿una virtud?}

Llegados a este punto, Maclntyre relaciona el concepto de patriotismo con dos formas antagónicas de entender la moralidad, la liberal y aquella otra que hace del patriotismo una virtud.

Una de las explicaciones de la moralidad más extendidas en el mundo contemporáneo es la liberal. La moralidad liberal presenta la decisión moral como una decisión en la que no pueden entrar elementos que provengan del interés personal o de la situación del agente moral. El modelo de persona, tal y como es concebido por el proyecto liberal, muestra a un sujeto autónomo y universal en las decisiones del cual no tienen cabida los elementos particulares. La razón tiene que prescindir de todas las particularidades constitutivas para hacerse universal, desinteresada y neutral.

Para Maclntyre, la moralidad liberal entra en conflicto con el concepto de patriotismo. La actitud patriota exige la consideración de la nación, el tiempo en que alguien vive, la cultura en la que está inmerso, y las costumbres que han flanqueado el desarrollo de su vida. El mismo concepto de lo que se considera un acto virtuoso se gesta en este ámbito de particularidades. Por lo tanto, desde la perspectiva de la moralidad liberal, concluye el autor, “(...) el punto de partida moral y el punto de partida patriótico son sistemáticamente incompatibles." (Maclntyre, 1984: 5).

Maclntyre ofrece dos ejemplos de la incompatibilidad entre el patriotismo y la moralidad liberal:

a) En caso de conflicto a la hora de obtener un bien escaso (el petróleo, por ejemplo) el punto de partida de la decisión moral- impersonal y universal- entra en conflicto con la actitud patriota que fundamentará cualquier decisión que se tome en interés de la nación particular. 
b) Otra circunstancia en que se pone de relieve la incompatibilidad de la actitud patriota con el punto de vista universal de la moralidad es el que se puede encontrar cuando se confrontan los diferentes conceptos que las comunidades tienen sobre cuál es la mejor forma de vivir. Cada comunidad expresa este ideal radicándolo en sus características y no en un modelo ideal universalista. El punto de vista moral impersonal exige neutralidad, es decir, dejar de lado tanto los intereses particulares como las creencias sobre cuál es la mejor forma de vida defendida por una comunidad, mientras que la actitud patriota abogará por un punto de vista que es el expresado por la comunidad propia.

Dentro de la perspectiva de la moralidad impersonal Maclntyre reúne tres posiciones filosóficas: el kantismo, el utilitarismo y el contractualismo, teorías que, a pesar de las diferencias importantes que las separan, comparten los siguientes rasgos comunes:

a) Para estas posiciones filosóficas la moralidad está constituida por un conjunto de reglas que toda persona racional aceptaría bajo ciertas condiciones ideales.

b) Estas reglas morales obligan y expresan neutralidad entre intereses en conflicto.

c) Estas reglas también son neutrales en cuanto a las concepciones rivales sobre cuál es la mejor forma de vivir la vida humana, esto quiere decir que no expresan ninguna forma particular de ideal moral.

d) Cada sujeto moral es uno sólo, individual, y cuenta como uno sólo.

e) Todos los sujetos morales tienen la misma clase de relación con las mismas leyes; esto significa que las leyes dejan fuera cualquier tipo de particularismo.

Está claro que si la moralidad se define en estos términos, ser moral puede llegar a ser incompatible con ser patriota, no sólo a la hora de entender el patriotismo como una virtud, sino también en el momento de materializar las exigencias del ser patriota. Los deberes hacia la patria exigen que las decisiones se tomen apuntando a lo mejor para la patria y esto no siempre encajará con lo que es mejor para cualquier patria. ¿Cómo hacer compatible la decisión patriótica con la decisión neutral y universalista que para la moralidad liberal es la decisión moral? Este planteamiento 
obliga a situar el patriotismo fuera de la moralidad, o lo que es lo mismo, anteponer una decisión universal y neutral -moral- a la decisión patriótica.

Ahora bien, hay otro planteamiento moral que no es incompatible con el patriotismo.

Maclntyre se sirve de dos palabras fundamentales para señalar las discrepancias básicas entre la moralidad liberal y una formulación de la moralidad contextualizada: donde se aprenden los principios morales que guían nuestros actos, y de quienes se aprenden estos principios morales.

Los principios morales aprendidos se adquieren en el seno de una comunidad en la que los principios se han ido formulando y reformulando en virtud de las situaciones, las dificultades y la historia vivida por la comunidad. Aunque se puedan encontrar principios morales transcomunitarios, el contenido de estos principios y la forma que toma su aplicación están estrechamente ligados al desarrollo de cada comunidad. No hay un aprendizaje en abstracto, dice Maclntyre, todo aprendizaje está siempre contextualizado comunitariamente: “(...) lo que aprendo como guía de mis actos y como modelo para evaluarlos no es la moralidad como tal, sino siempre una moralidad muy específica de algún orden social muy específico." (MacIntyre, 1984: 9).

Los autores que defienden la moralidad liberal están de acuerdo en que este es el punto de partida del aprendizaje moral, pero mantienen que la plena madurez moral no se logra hasta que se dejan atrás las particularidades de la comunidad en la que radican las normas morales aprendidas. Así, se expresa, por ejemplo, en la formulación del estadios de progreso moral expuestos por L. Kohlberg según los cuales se va progresando moralmente a medida que el sujeto es capaz de ir sustituyendo las decisiones interesadas por otras que se fundamentan únicamente en el universal común. El individuo pasa por una serie de fases que empiezan por lo que Kohlberg denominó 'nivel pre-convencional', caracterizado por las decisiones egocéntricas, hasta llegar al 'nivel moral post-convencional' o nivel basado en principios en el que las 
decisiones que se toman se atienen sólo al reconocimiento racional de la validez de los principios morales universales.

Macintyre se opone al concepto de moralidad como universalidad despersonalizada porque, desde su punto de vista, las normas morales no son lo primeramente aprendido; aquello con que se entra en contacto y que servirá para justificar las normas morales son los bienes; el aprendizaje de que algo es bueno es siempre un aprendizaje concreto que se descubre en las relaciones sociales que se mantienen en el seno de la comunidad. El vínculo que una persona tiene con las normas morales se fundamenta en la comunidad a la que pertenece: “(...)(el ser humano) privado de la vida de esta comunidad, no tendría razones para ser moral." (Maclntyre, 1984: 10). Además, añade el autor, cumplir las normas morales es pesado y no siempre se está dispuesto a hacerlo; en estos casos, aquellos miembros de la comunidad que nos rodean ponen remedio a la tentación en cuanto que nos ayudan a superar nuestra debilidad moral. Mostrando este interés por nuestra moralidad, un interés que no tiene nada que ver con el beneficio, los demás demuestran también el respeto que nos tienen. Desde este punto de vista, la moralidad se encuentra estrechamente unida a la particularidad de la comunidad y no a la universalidad impersonal que defiende la tesis liberal. Para Maclntyre, todo lo que rodea la vida moral de la persona tiene que ver con la comunidad, porque el ser humano es producto de esta comunidad. Se aprenden las normas morales dentro de una comunidad específica, y se aprenden tal como se materializan en aquella comunidad. A la hora de justificar las normas morales, es indispensable referirse a los bienes particulares valorados como tales dentro de la comunidad. De este modo, se puede decir que la vida moral del agente viene estimulada y sostenida por la comunidad en la que se encuentra.

La moralidad dentro de la cual el patriotismo se considera una virtud defiende que las reglas morales se justifican “(...) si y sólo si producen y, en parte, constituyen una forma de vida social compartida los bienes de la cual son directamente disfrutados 
por los habitantes de las comunidades particulares en las que la vida social es de esta clase." (Maclntyre, 1984: 12). Dentro de este contexto, todo aquello que la comunidad exija de un agente moral se justifica por su relación con la comunidad; la comunidad es el contexto de apelación de las decisiones morales. El patriotismo es, de hecho, exigible porque es un deber mostrar celo por todo aquello que interese a la comunidad puesto que es el elemento referencial del individuo.

La tradición liberal, en cambio, pide al agente moral una respuesta racional, abstracta que deje de lado cualquier clase de particularidad porque esta es la condición indispensable de su libertad moral. Sólo en la medida en que se trascienden las condiciones sociales, políticas o económicas, y la situación personal que rodea la decisión moral, ésta puede considerarse totalmente libre.

Desde este planteamiento, el patriotismo, anclado como está a una realidad política y social particular, a la que es leal y que no somete a crítica, recibe las críticas de la moralidad liberal. ¿Qué puede responder la moralidad del patriotismo?

A pesar de las divergencias que el patriota pueda tener respecto a la nación a la que pertenece, su actitud acrítica se extiende, como dice Maclntyre, "a la nación concebida como proyecto" (Maclntyre, 1984: 12), un proyecto que empezó en el pasado, se ha desarrollado hasta el presente, y al amparo del cual se han conformado los miembros que la integran sus instituciones. El patriota establece una conexión entre el pasado de su nación, un pasado que ha formado su personal identidad política y moral, y el proyecto de futuro de la nación, un proyecto que el patriota se encuentra comprometido a llevar a cabo. La lealtad del patriota lo es respecto a este proyecto que se traza del pasado hacia el futuro, lo cual no impide que el patriota sea crítico con todo aquello que, dentro de la nación, estorbe este proyecto. No hay nada incompatible con ser patriota y, al mismo tiempo, crítico con el político de turno o con la forma de gobierno de la comunidad. Para ilustrarlo Maclntyre cita cuatro patriotas, dos de los cuales fueron políticos, Charles de Gaulle ${ }^{2}$ y Otto von Bismarck ${ }^{3}$, y los otros

\footnotetext{
${ }^{2}$ Político francés (1890-1970) que fue presidente de la República Francesa entre los años 1958 i 1969.
} 
dos, Charles Péguy ${ }^{4}$ y Adam von Trott $^{5}$, críticos con los políticos de sus naciones. El arraigo a una determinada comunidad no impide que se rehúsen algunas cosas; los modelos proporcionados por una comunidad pueden servir para criticarla cuando se considera que aquélla ha dejado de cumplirlos; en este caso, el patriota es un crítico interno. El patriotismo es la consecuencia natural de entender la vida propia en términos de una narración que se desarrolla y se expresa relacionándose con los demás. Nuestra identidad deriva de una larga sucesión de hechos que llegan hasta el presente. La historia de cada vida está radicada y toma sentido dentro del entramado de historias familiares y de relaciones sociales que se mantienen con los demás. La dimensión central de la vida moral se pierde si se ignora que la vida individual está tejida con la historia de la nación a la que se pertenece. (Maclntyre, 1984: 16) Esta es la clave para entender cuáles son las obligaciones que tenemos con los demás y que ellos tienen con nosotros, y también para entender todo lo que debemos a nuestra nación. Está claro pero, señala Maclntyre, que el patriotismo es una respuesta racional a una determinada clase de comunidad a la que una persona se siente vinculada de una forma radical. El patriotismo se considera una virtud porque, en una situación determinada, inclina al ciudadano a cumplir con los deberes que éste tiene para con su patria, en un claro reconocimiento por su parte de que existe un débito y algo que salvaguardar. Maclntyre refleja aquí una forma de entender la moralidad que ya se encuentra en un texto clásico, Los deberes, de Cicerón. En el capítulo primero de esta obra Cicerón dice: "En el marco mismo de la comunidad social hay una jerarquía de deberes que hace posible entender cuál aventaja a cuál: los primeros deberes se refieren a los dioses inmortales, los segundos a la patria, los terceros a los padres, y después, -siguiendo un orden- al resto de humanos." (CICERÓN: 84)

La moralidad que hace del patriotismo una virtud estima que los deberes debidos a la patria y a los demás son antes que los debidos a la humanidad, mientras

\footnotetext{
3 Político alemán (1815-1898) considerado el fundador del Estado Alemán moderno.

${ }^{4}$ Escritor francés (1873-1914) afín al socialismo.

${ }^{5}$ Político y abogado alemán (1909-1944) ejecutado por participar en un complot contra Adolf Hilter.
} 
que una moralidad universalista excluye todo lo cercano y subjetivo como fundamento de decisión moral.

Mientras el peligro que la moralidad liberal ve en el patriotismo está en su actitud acrítica con la comunidad, MacIntyre pone de relieve que el peligro que supone el liberalismo moral es que su criticismo racional afloje los vínculos sociales y morales de la comunidad. (Maclntyre, 1984: 18).

Presentados tal como lo ha hecho el autor, el liberalismo moral y el patriotismo son incompatibles, pero la paradoja es que, en las sociedades occidentales ambos conviven mantenidos por las mismas personas. Por un lado, se da amparo a una moralidad impersonal y descontextualizada, y por el otro se defiende un patriotismo que está totalmente contextualizado.

\section{Conclusiones}

Los dos modelos de moralidad que expone Maclntyre entienden de modo diferente el concepto de 'patriotismo'. Así, mientras la universalidad y neutralidad de la moralidad liberal es incompatible con el patriotismo, porque éste nunca puede ser ni neutral ni universal, la moralidad comunitaria no solamente lo hace compatible, sino aun exigible. La paradoja con la que Maclntyre concluye su artículo pide una nueva reflexión para explicar de qué manera se puede hacer compatible la defensa de un punto de vista moral neutral y universalista con una actitud patriótica.

Si la decisión moral tiene que cumplir con los requisitos de ser universal y neutral, no cabe la decisión patriótica, porque es interesada y contextualizada, por lo tanto, se tiene que concluir que, desde este punto de vista, la moralidad liberal no puede incluir el patriotismo. Pero si se desampara el patriotismo cuando no se le da un lugar dentro de la moralidad, entonces, el patriotismo queda relegado a una actitud psicológica o política. El reconocimiento de los deberes morales hacia la comunidad integra al patriotismo en la moralidad, pero entonces, la moralidad no puede ser universal y neutral. 
Por otro lado, es evidente que para que se reconozca que alguien tiene deberes morales para con la comunidad, ésta tiene que tener ciertas características, o lo que es lo mismo, el patriotismo no puede manifestarse hacia cualquier clase de comunidad. Pueden establecerse una serie de 'prerequisitos del patriotismo', de condiciones necesarias para que nazca el patriotismo:

a) Para llegar al patriotismo hay que sentirse parte de un proyecto que proviene del pasado y que pide la participación activa de cada cual para su continuidad.

b) Las personas tienen que sentirse arraigadas, identificadas con los valores, los ideales y el sentido de vida que se defiende y se vive en la comunidad donde se está.

c) Sentir y creer son las condiciones para admitir y cumplir con los deberes morales hacia la comunidad.

Maclntyre sitúa el concepto de patriotismo dentro de la tradición: ser patriota es la consecuencia natural del concepto de tradición; si negamos la tradición, no se puede mantener el patriotismo.

Volvamos a la paradoja mencionada por Maclntyre: el hecho de que muchas personas se digan patriotas al mismo tiempo que defienden una moralidad universal y neutral. Quizás la paradoja desaparece si, como lo hace Maclntyre, se afirma que ninguna moralidad puede ser neutral y descontextualitzada porque toda moralidad traduce las características de una comunidad concreta: el liberalismo moral, como cualquier otra tradición, tiene su propio contexto:

“(...) no existe tal fundamento neutral, no cabe apelar a la racionalidad práctica o en la justicia como tales a las que toda persona racional, por su racionalidad, estaría obligada a ser leal. En su lugar hay, sólo, la racionalidad práctica de esta o de aquella tradición y la justicia de esta o de aquella tradición." (MacINTYRE, 1988: 346).

Si la idea de la moralidad liberal en términos de una moralidad fuera de cualquier tradición es falsa porque ella misma es otra tradición, la paradoja desaparece, no dentro de la pretensión de la moralidad liberal, pero sí a efectos 
prácticos; la moralidad liberal es compatible con el patriotismo cuando este patriotismo defiende una comunidad convencida de los principios liberales.

Maclntyre escribe teniendo por referente la sociedad norteamericana donde la expresión 'patriotismo americano' es corriente; un concepto que se distingue del de 'nacionalismo americano' en cuanto que en el primero se pone énfasis en los valores y las ideas que guiaron la fundación y la independencia de los Estados Unidos, algo que no sucede con el segundo.

El 1945 George Orwell escribía:

“Con 'nacionalismo' me refiero al hábito de identificarse con una sola nación u otra unidad, poniéndola más allá del bien y del mal y no reconociendo otro deber que el de promover sus intereses. (...) Con 'patriotismo' me refiero a la lealtad hacia un lugar en particular y hacia una forma de vida particular que se cree que es la mejor del mundo, pero que no se desea imponer a los demás. Por su naturaleza, el patriotismo es defensivo, tanto militar como culturalmente. Por otro lado, el nacionalismo es inseparable del deseo de poder. El proyecto permanente de todo nacionalista es asegurar más poder y más prestigio, no para sí mismo, sino para la nación u otra unidad en la que ha escogido sumergir su propia individualidad."

Leyendo el texto de Maclntyre y las palabras de Orwell se constata la diferencia de usos terminológicos entre la sociedad norteamericana y la española. Sin duda, la diferencia tiene que ver con el pasado histórico de las dos comunidades, un pasado que condiciona, por ejemplo, que en estos días que la sociedad catalana está viviendo, donde se exaltan y se destacan la calidades y características propias de Catalunya, nadie hable nunca de patriotismo, y el único término empleado para mostrar el afecto y la lealtad a la patria sea sólo el de 'nacionalismo'.

El concepto de patriotismo, claramente expuesto por Maclntyre, radica en el concepto de una comunidad definida en los términos de una tradición. En este sentido, se puede equiparar 'comunidad' a nación', y ser ésta la patria a la que el patriota se siente afectivamente vinculado. Sin embargo, nos salen al encuentro otros dos 
conceptos de más difícil clasificación, el de 'país' y el de 'sociedad' cuyo vínculo con los dos anteriores puede ser, en algunos casos, problemático.

La situación más simple es aquélla en la que puede establecerse una relación de equivalencia entre país, sociedad y la nación porque tienen las características que Maclntyre atribuye a la comunidad. En este caso, ser un patriota es mostrar una actitud favorable a reconocer y a cumplir los deberes para con la patria que coincide (aunque desde otro punto de vista) con el país y la nación.

Sin embargo, en algunos casos, la equivalencia entre lo términos apuntados puede no ser tal. Así, por ejemplo, en un mismo país puede haber diferentes naciones, sociedades y expresiones patrióticas que no se funden en un solo patriotismo o ni siquiera en un nacionalismo común. La causa de esta variedad de patriotismos no es debida tanto al hecho de que las sociedades occidentales sean plurales, es decir, que en ellas convivan diferentes comunidades con tradiciones diferentes, cuanto a razones lingüísticas, culturales e históricas. De este modo, pese a las diferentes tradiciones que integran la sociedad norteamericana puede hablarse de nacionalismo y de patriotismo americano. Sin embargo, si nos referimos a España, por ejemplo, dentro de un mismo país hay que referirse a diferentes naciones puesto que son diferentes las lenguas, la cultura y la trayectoria histórica de cada una de las naciones. En la sociedad española conviven diferentes tradiciones, pero el concepto de nación no corre paralelo al de la tradición puesto que, en el caso de Catalunya, por ejemplo, la nación o el nacionalismo está sustentado por diferentes tradiciones (en el sentido de Maclntyre). De ahí que pueda hablarse de diferentes patriotismos. Sin embargo, aunque en España el debate sobre los nacionalismos está hoy muy presente en la vida política y ciudadana, casi nadie escoge el término 'patriota' para referirse a su fidelidad a la nación o al reconocimiento de sus deberes para con la patria. Razones históricas han socavado el significado de 'patria' o de 'patriota' puesto, que en el pasado político de España, se utilizaron estos términos para ignorar las diferentes nacionalidades que constituían la realidad del país con la intención de crear la ficción de una única nación. 
El nacionalista que hoy reclama poder político, legal, etc. para su nación es un patriota en los términos que Maclntyre define el término porque se siente afectivamente ligado a su nación, que es su patria, y está convencido que merece la pena salvaguardar su identidad.

\section{Bibliografía}

Cicerón, (1978): Los deberes. Barcelona: Vosgos.

Maclntyre, A., (1984): After Virtue. Notre Dame: Notre Dame University Press.

Maclntyre, A., (1984): “Is Patriotism a Virtue?" The Lindley Lecture: Department of Philosophy, University of Kansas, p. 3-20.

Maclntyre, A., (1988): Whose Justice? Which Rationality. London: Duckworth. Orwell,G., (1945) “Notes On Nationalism”.

http://thelittlebook.blogs.fi/2009/12/06/george-orwell-on-patriotism-7521607/

Doutora em Filosofia Professora do Departamento de Filosofia Teórica e Prática da Universidade de Barcelona E-mail: mauri@ub.edu 